\title{
Grupo Gerdau: uma análise do crescimento produtivo e da expansão internacional
}

\author{
Felipe Athia* \\ Armando Dalla Costa*
}

RESUMO - Dentro de 50 anos, o Grupo Gerdau foi capaz de transformar uma fábrica de pregos em um dos maiores conglomerados industriais do Brasil e da América Latina, estando presente em 14 países e exportando para os cinco continentes. É considerado, atualmente, o $13^{\circ}$ maior produtor de aço do mundo, tendo produzido aproximadamente 18 milhões de toneladas em 2007, possuindo diversas fábricas no exterior. A proposta deste trabalho é realizar uma análise da expansão produtiva e comercial da empresa e, ainda, identificar os motivos e como ocorreu seu processo de internacionalização.

Palavras-chave: Gerdau. Crescimento da firma. Internacionalização das empresas. Economia industrial. Siderurgia

\section{INTRODUÇÃO}

O Grupo Gerdau é um dos maiores conglomerados industriais do Brasil e da América Latina, estando presente em 14 países: Argentina, Brasil, Canadá, Chile, Colômbia, Espanha, Estados Unidos, Guatemala, Índia, México, Peru, República Dominicana, Uruguai e Venezuela. De acordo com a World Steel Association (2009), o Grupo ocupa o $13^{\circ}$ lugar no ranking mundial de produtores de aço, produzindo cerca de 18 milhões de toneladas no ano de 2007, sendo considerado o maior produtor de aço do Brasil e das américas.

As atividades do Grupo iniciaram em 1901 com a aquisição da "Fábrica de Pregos Ponta de Paris" por Johann Gerdau e atualmente, pouco mais de 100 anos depois, é uma empresa que possui ações listadas nas bolsas de Nova Iorque, Madri, Toronto e São Paulo e exporta para os cinco continentes.

Dentre os principais motivos para o seu crescimento acelerado, pode-se destacar a diversificação de produtos - o Grupo iniciou suas atividades na produção de pregos e, atualmente, seus produtos são destinados aos mais diversos setores, a saber: agropecuária, construção civil, indústria, mineração, automotivo e infraestrutura -, a compra de

\footnotetext{
* Estudante de Economia da UFPR - Universidade Federal do Paraná. Endereço eletrônico: felipe@athia.com.br.

** Pós-Doutor pela Université de Picardie Jules Verne, Amiens, França. Doutor pela Université Paris III (Sorbonne Nouvelle). Professor no Departamento de Economia e no Programa de Pós-Graduação em Desenvolvimento Econômico da UFPR. Coordenador do Núcleo de Pesquisa em Economia Empresarial (www.empresas.ufpr.br). Endereço eletrônico: ajdcosta@ufpr.br.
} 
concorrentes, construção de novas plantas industriais, expansão geográfica, investimentos em $\mathrm{P} \& \mathrm{D}$, introdução de novos processos e a internacionalização da empresa.

Embora sua entrada no mercado de capitais tenha se iniciado em meados do século XX, em 1947 na Bolsa de Valores de Porto Alegre, a internacionalização da empresa ocorre muito depois, no final de 1980, com a aquisição da siderúrgica Laisa, no Uruguai (GERDAU, 2001). O passo seguinte em direção à internacionalização da empresa foi um pouco mais longo: o Grupo Gerdau adquiriu a siderúrgica canadense Courtice Steel Inc. em 1989, uma indústria de proporções relativamente maiores que a anteriormente adquirida no Uruguai.

O volume de produção de aço aumentou consideravelmente após o início do processo de internacionalização: em 1980 eram produzidas cerca de 1,3 milhões de toneladas de aço; em 1988, um ano antes da aquisição da siderúrgica canadense Courtice Steel Inc., atingiu a meta de dois milhões de toneladas; em 1999 foram produzidas cerca de 5 milhões de toneladas; em 2000, com a aquisição da AmeriSteel Corp. já efetivada, a produção subiu para 7 milhões de toneladas; por fim, em 2008, após diversas aquisições nacionais e estrangeiras e ampliações de plantas industriais, a empresa totalizou 19,6 milhões de toneladas (GERDAU, 2009c).

Este artigo tem por objetivo analisar a expansão produtiva do Grupo Gerdau, enfatizando o processo de internacionalização das atividades a partir do início da década de 1980.

\section{A GERDAU NO BRASIL: UM PANORAMA DO PERÍODO 1901-2008}

\subsection{AS ORIGENS E A EXPANSÃO DO GRUPO (1901-1980)}

As atividades do Grupo Gerdau iniciaram em 1901, quando o imigrante alemão Johann Gerdau (João Gerdau) comprou uma antiga fábrica de pregos fundada em 1891, a Fábrica de Pregos Pontas de Paris, em Porto Alegre - RS. Pouco depois, em 1903, João Gerdau passou a responsabilidade da empresa para um de seus filhos, Hugo Gerdau, que posteriormente assumiria o controle da mesma.

A empresa produzia pregos, utilizando matéria-prima vinda do exterior, especialmente dos Estados Unidos e da Europa. No início, os pregos eram vendidos somente ao interior do estado do Rio Grande do Sul, mas, com o tempo, o produto começou a chegar aos outros estados e até mesmo às regiões Norte e Nordeste, através dos navios da Companhia Nacional de Navegação Costeira, conhecida popularmente pelo nome de "Ita” (GERDAU, 2001). 
A modernização e a eletrificação das máquinas só aconteceria em 1952, quando a antiga fábrica, então localizada na Rua Voluntários da Pátria, mudou para a Avenida dos Farrapos, na área central de Porto Alegre, devido à aquisição da Siderúrgica Riograndense. Assim, pode-se constatar que a estrutura da indústria permaneceu praticamente inalterada por quase meio século.

A entrada do Grupo Gerdau no ramo siderúrgico ocorreu em 1948, com a aquisição da Siderúrgica Riograndense. Essa compra ocorreu devido à escassez de matéria-prima para a produção de pregos logo após a Segunda Guerra Mundial, levando a empresa a diversificar suas atividades verticalmente. "A integração para trás, como outras formas de diversificação, é promovida por um desejo de evitar os riscos das flutuações e para aumentar a segurança da firma diante de incertezas gerais" (PENROSE, 2006, p.227).

Em 1954, devido à pequena dimensão da Siderúrgica Riograndense, a diretoria do Grupo na época, Curt Johannpeter e Roberto Nickhorn, iniciou um projeto de expansão, cujas obras começaram em 1955. A chamada Usina Rio dos Sinos (ou Usina II da Siderúrgica Riograndense), localizada em Sapucaia do Sul, a 25 quilômetros de Porto Alegre, entrou em funcionamento em 1957. A nova unidade ampliou a capacidade de produção e introduziu o processo de lingotamento contínuo ${ }^{57}$, iniciativa pioneira na América Latina. O sucesso da nova fábrica não significou o abandono da unidade de Farrapos (Usina I), que continuaria a operar por muito tempo, embora estivesse claro que a partir daquele momento, a Usina de Sapucaia do Sul (Usina II) seria o "pulmão” das atividades industriais da empresa (GERDAU, 2001).

Embora a Gerdau já contasse com representantes em diversas áreas do país e seus produtos chegassem ao Norte e Nordeste, a principal área de atuação comercial estava concentrada no Sul do país, fazendo com que, novamente, Curt Johannpeter e Roberto Nickhorn se empenhassem em abrir espaço nas áreas centrais do país. Neste contexto, em 1967, a Gerdau comprou a Indústria de Arames São Judas Tadeu, em São Paulo que, na época, era a maior fabricante de arame farpado do Brasil. Contudo, devido a diversos fatores, em sua maioria econômicos, a fábrica acabou desativada e suas máquinas enviadas para a Usina II em Sapucaia do Sul e Recife. Posteriormente foi renomeada Comercial Gerdau, passando a ser o segmento de distribuição de produtos siderúrgicos no Brasil (BARBOSA, 2004).

\footnotetext{
${ }^{57}$ Processo que continuamente produz placas ou tarugos a partir do aço líquido vazado através de um molde.
} 
Pouco tempo depois do fracasso da compra da Indústria de Arames São Judas Tadeu, a Gerdau resolveu ir mais longe e, em 1969, comprou a Siderúrgica Açonorte, em Pernambuco. Entretanto, o Grupo ainda estava focado no mercado "central". Assim, em 1971, formou uma joint venture com o Grupo Thyssen A.G., da Alemanha e, financiado pelo BNDES adquiriu a COSIGUA - Companhia Siderúrgica da Guanabara. Em 1979, o Grupo Thyssen A.G. se retirou da parceria, fazendo com que o Grupo Gerdau obtivesse controle total da COSIGUA. Além dessas aquisições, a década de 1970 foi marcada pela aquisição de outras duas siderúrgicas: a Siderúrgica Guaíra, no Paraná (1972) e a Companhia Siderúrgica de Alagoas - COMESA (1974), embora só fossem entrar em funcionamento em 1981.

O fim da década de 1970 foi histórico para o Grupo, não só pelo início do processo de internacionalização, mas também pela marca de um milhão de toneladas produzidas.

FIGURA 1 - A EVOLUÇÃO DA PRODUÇÃO NO PERÍODO 1948-1980

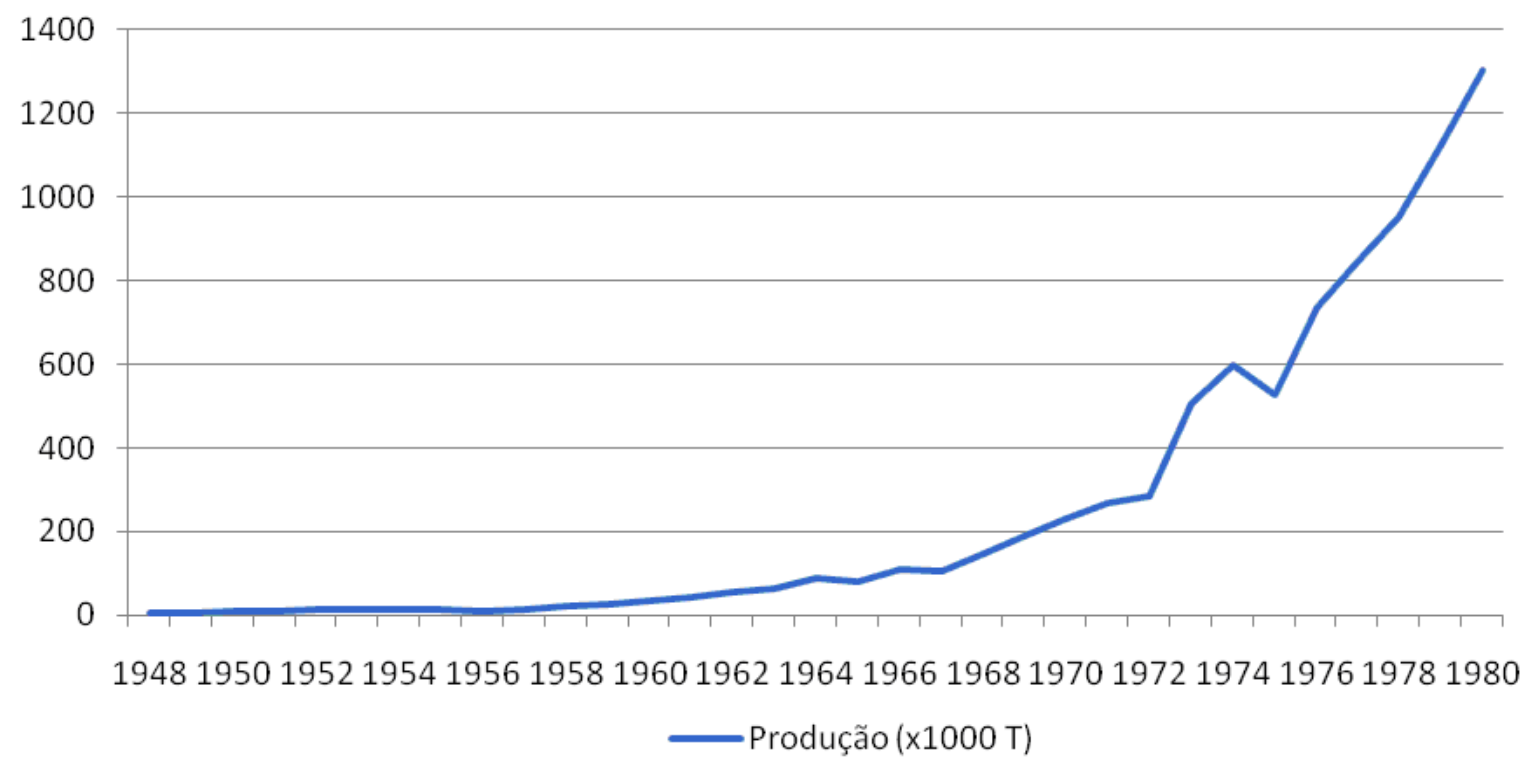

FONTE: Elaboração dos autores a partir dos dados da GERDAU, 2009a (não incluem joint-ventures).

\subsection{O GRUPO GERDAU NO BRASIL APÓS 1980 (1980-2008)}

Desde o início da década de 1980, o Grupo apresentou novos objetivos: qualidade e produtividade se tornaram metas principais, deixando a ampliação da capacidade instalada em segundo plano, além de uma preocupação mais sólida em relação ao meio-ambiente. Nessa época, já eram apresentados 34 diferentes produtos entre vários tipos de arames, barras, cantoneiras, cordoalhas, cabos de aço, correntes, perfis, pregos, rebites, telas soldadas e vergalhões - visando diferentes mercados, como, por exemplo, o setor agropecuário e de 
construção civil, indústria e mineração (GERDAU, 2001). Essa diversificação horizontal foi uma das estratégias adotadas pela Gerdau para conquistar novos mercados.

Foi naquele contexto que a Gerdau iniciou, em 1981, um processo de expansão geográfica no país, iniciando com a construção da Siderúrgica Cearense em Maracanaú, próximo a Fortaleza. A década de 1980 foi marcada, portanto, por aquisições e construções de novas plantas industriais.

Dentre as diversas aquisições e construções realizadas nesse período (1980-2008), além das já mencionadas, cabe ressaltar a compra - através do processo de privatização - da USIBA (1989), da COSINOR (1991) e da Aços Finos Paratini, no Rio Grande do Sul (1992), a aquisição da Siderúrgica Pains, em Minas Gerais, renomeada Gerdau Divinópolis, da Açominas (2001), a construção da Gerdau Araçariguama (2001), a aquisição da Maranhão Gusa S.A. em Macabeira-MA (2003) e também a construção de uma segunda planta industrial em Araçariguama, denominada Gerdau São Paulo (2006).

Sobre as aquisições, Penrose (2006) afirma que têm participação importante nas atividades de diversificação, visto que

Os custos imediatos e as dificuldades administrativas e técnicas do ingresso num novo campo de atividade poderão ser substancialmente reduzidos se uma firma conseguir adquirir outro empreendimento em atividade.

TABELA 1 - ANO DE FUNDAÇÃO E/OU AQUISIÇÃO E LOCALIZAÇÃO DAS EMPRESAS DO GRUPO GERDAU NO BRASIL - 1901-2006

\begin{tabular}{|c|c|c|c|}
\hline Ano & Empresa & Localização & Processo \\
\hline 1901 & Fábrica de Pregos Pontas de Paris & Porto Alegre-RS & Aquisição \\
\hline 1948 & Siderúrgica Riograndense & Porto Alegre-RS & Aquisição \\
\hline 1957 & Usina Rio dos Sinos & Sapucaia do Sul-RS & Construção \\
\hline 1967 & Indústria de Arames São Judas Tadeu & São Paulo-SP & Aquisição \\
\hline 1969 & Siderúrgica Açonorte & Recife-PE & Aquisição \\
\hline 1971 & COSIGUA & Santa Cruz-RJ & Joint-venture \\
\hline 1972 & Siderúrgica Guaíra & Araucária-PR & Aquisição \\
\hline 1974 & COMESA & Atalaia-AL & Aquisição \\
\hline 1981 & Siderúrgica Cearense & Maracanaú-CE & Construção \\
\hline 1985 & Siderúrgica Hime & São Gonçalo e Nova Iguaçú-RJ & Aquisição \\
\hline 1986 & Usina Siderúrgica Paraense (USIPA) & Contagem-PA & Aquisição \\
\hline 1986 & Companhia Brasileira de Ferro (CBF) & Viana-ES & Aquisição \\
\hline 1989 & USIBA & Salvador-BA & Aquisição \\
\hline 1991 & Cosinor & Recife-PE & Aquisição \\
\hline 1992 & Aços Finos Piratini & Charqueadas-RS & Aquisição \\
\hline 1994 & Siderúrgica Pains & Divinópolis-MG & Aquisição \\
\hline 2001 & Siderúrgica Araçariguama & Araçariguama-SP & Construção \\
\hline 2001 & Açominas & Ouro Branco-MG & Aquisição \\
\hline 2003 & Comercial Gerdau Cachoeirinha & Cachoeirinha-RS & Construção \\
\hline 2003 & Maranhão Gusa S.A. & Macabeira-MA & Aquisição \\
\hline 2006 & Gerdau São Paulo & Araçariguama-SP & Construção \\
\hline
\end{tabular}


FONTE: Elaboração dos autores a partir dos dados da GERDAU, 2009c.

Além disso, estabelecimentos podem ser adquiridos usualmente por um valor menor que seu custo de reprodução, obtendo-se, ainda, valiosa posição de mercado e substancial redução das pressões competitivas, além de “adquirir uma 'equipe' administrativa com experiência junto com um quadro técnico e uma forca de trabalho já experimentados" (PENROSE, 2006, p.201).

\section{A INTERNACIONALIZAÇÃO DO GRUPO GERDAU}

\subsection{O INÍCIO: A ENTRADA NO MERCADO URUGUAIO}

As empresas multinacionais iniciaram o processo de investimento além de suas fronteiras em larga escala após a Segunda Guerra Mundial. O crescimento dos investimentos estrangeiros provenientes de empresas deste momento até a Primeira Crise do Petróleo, ocorrida em 1973, apresentou taxas superiores às do comércio internacional, embora o crescimento tenha se dado com maior significância a partir dos anos 1980 (DALLA COSTA, 2007). O crescimento da produção internacionalizada pode ser interpretado como uma resposta às mudanças no ambiente econômico mundial, caracterizado pelas mudanças tecnológicas, pela liberalização política e pela competição crescente (CORREA \& LIMA, 2006).

A expansão econômica iniciada em 1967 atingiu seu auge em 1973, sendo popularmente denominado como o período do "milagre econômico". A partir de 1974 iniciou um processo de declínio que culminou com a recessão de 1981. Este período de declínio foi marcado, ainda, pela tendência ascendente da taxa de inflação, tornando-se um mecanismo de defesa do processo de acumulação (BRESSER-PEREIRA, 2003). As décadas de 1960 e 1970 podem ser interpretadas como a primeira fase do investimento de empresas brasileiras no exterior (IGLESIAS \& VEIGA, 2002). Embora o montante de capital investido em atividades no exterior tenha sido significativo entre o final dos anos 1960 e o início da década de 1970, esse volume de capital passou a crescer rapidamente a partir de 1977 visto que, assim como a Gerdau, muitas empresas decidiram optar pela diversificação das atividades no exterior visando diminuir os riscos relacionados aos problemas econômicos da economia brasileira (LOPEZ, 1999 apud BARBOSA, 2004) ${ }^{58}$.

${ }^{58}$ LOPEZ, A. El caso brasileño. In: CHUDNOVSKY, D.; KASACOFF, B.; LOPEZ, A. Las multinacionales latinoamericanas: sus estrategias en un mundo globalizado. Fondo de Cultura Económica, Buenos Aires, 1999. 
Neste aspecto, a inflação não foi o único problema de ordem econômica enfrentada durante o final da década de 1970 e início da década de 1980. Houve dificuldades com os instrumentos de promoção do comércio exterior e a estagnação da produção industrial, influenciando negativamente o ritmo da expansão das exportações de produtos brasileiros (IGLESIAS \& VEIGA, 2002).

O setor siderúrgico, como o restante da economia, sofreu com as condições macroeconômicas do período, observando-se intensa redução dos investimentos e o desajuste das contas internas e externas. Entretanto, na "contramão" da incerteza e da recessão, o Grupo Gerdau começou a procurar alternativas no mercado externo e foi naquele contexto que ocorreu a aquisição da siderúrgica uruguaia Laisa, em dezembro de 1980.

Embora a distância geográfica fosse curta, a já mencionada distância psíquica era significativa. Localizada em Montevidéu, apesar das dificuldades, a siderúrgica Laisa entrou em funcionamento em janeiro de 1981. A Laisa era uma siderúrgica de pequeno porte, adequada aos padrões do mercado uruguaio, produzindo cerca de sete mil toneladas/ano de aço e 5,5 mil toneladas/ano de laminados que, com o aparato tecnológico-administrativo proporcionado pelo Grupo Gerdau, foi possível modernizar a estrutura de produção e aumentar a competitividade comercial. Em dez anos a capacidade da Laisa era de 36 mil toneladas/ano de aço e 39 mil toneladas/ano de laminados.

Após cinco anos da aquisição a Laisa já dava lucro ao Grupo, mesmo com todos os problemas conjunturais encontrados. Além das dificuldades iniciais de ajustamento entre os administradores uruguaios e os novos gerentes brasileiros, havia ainda as decorrentes da má qualidade dos equipamentos e da falta de conhecimentos atualizados na produção do aço. Esses obstáculos foram superados e em 1997 a siderúrgica recebeu o Prêmio Nacional de Qualidade, entregue pelo governo uruguaio (GERDAU, 2001).

\subsection{A CONTINUAÇÃO: CHILE, ARGENTINA, CANADÁ E ESTADOS UNIDOS}

O passo seguinte em direção à internacionalização veio quase 10 anos mais tarde, em 1989 com a aquisição da siderúrgica canadense Courtice Steel Inc., com capacidade, na época da compra, de produção de 250 mil toneladas/ano de laminados longos. Embora os negócios no exterior representassem apenas 7,4\% da produção total em 1990 acredita-se, atualmente, que essas aquisições tenham sido um teste de qualificação empresarial, isto é, um teste da capacidade dos dirigentes de que novos riscos fossem assumidos para que se pudesse competir em um mundo cada vez mais globalizado. 
A estratégia amadureceu e ganhou contornos definidos: expandir a operação do grupo para fora do Brasil, mesmo continuando a crescer dentro do país. (GERDAU, 2001, p.164).

A partir da aquisição da Courtice Steel Inc., outros negócios no exterior rapidamente surgiram. Em cerca de sete anos, entre 1992 e 1999, foram adquiridas seis novas plantas: Indaq e Siderúrgica Aza, no Chile (1992), somando 75 mil toneladas/ano à produção do Grupo; Manitoba Rolling Mills (MRM), no Canadá (1995), aumentando a produção do Grupo em cerca de 7\% - 300 mil toneladas/ano de aço; Sociedad Puntana S.A. (SIPSA), e um terço do capital da SIPAR (em troca de um terço do capital da SIPSA), na Argentina (respectivamente, 1997 e 1998); por fim, a Gerdau comprou 75\% do capital da AmeriSteel Corporation - através da aquisição de $88 \%$ da FLS Holdings Inc. -, a segunda maior produtora de vergalhões dos Estados Unidos (1999).

A AmeriSteel Corp. foi a mais importante aquisição do Grupo até então, adicionando quase 2 milhões de toneladas/ano à sua produção. A AmeriSteel possuía quatro usinas na costa leste dos Estados Unidos: Jacksonville Steel Mill (em Baldwin, FL); Jackson Steel Mill (em Jackson, TN); Knoxville Steel Mill (em Knoxville, TN) e Charlotte Still Mill (em Charlotte, NC). Em 2000 a Gerdau adquiriu os 12\% restantes da FLS Holdings Inc., então propriedade da Kyoei Steel Ltd., que possuía 85\% do capital da AmeriSteel. No ano seguinte, 2001, a AmeriSteel comprou a siderúrgica Georgia Steel Mill, em Cartersville, GA.

Em 2002, foi fechado um acordo visando a união dos ativos da Gerdau na América do Norte, isto é, a Gerdau Courtice Steel (adquirida em 1989), a Gerdau MRM (comprada em 1995) e a Gerdau AmeriSteel (adquirida em 1999) com os ativos da Co-Steel. Foram incorporadas posteriormente ao novo grupo - denominado Gerdau AmeriSteel -, quatro siderúrgicas, três nos Estados Unidos (Sayreville Steel Mill, em Sayreville, NJ; Perth Amboy Steel Mill, em Perth Amboy, NJ; e Gallatin Steel Company, em Ghent, KY; sendo a última uma joint venture entre Gerdau AmeriSteel e Dofasco Inc.) e uma no Canadá (Whitby Steel Mill, em Whitby, ON). Com a unificação das atividades na América do Norte, a Gerdau tornou-se a segunda maior produtora de aços longos na América do Norte, com capacidade de 5,9 milhões de toneladas/ano de aço bruto e 5,6 milhões de toneladas/ano de produtos laminados.

Embora a década de 2000 tenha sido importante pela expansão em direção a mercados "novos", como o Peru (Empresa Siderurgica Del Perú, 2006), Espanha (GSB Acero, 2006), México (Siderúrgica Tultitlan, 2007), República Dominicana (INCA, 2007), Ásia (joint venture com o Kaylani Group, 2007) e Guatemala e Honduras (Corporación 
Centroamericana Del Acero, 2008); pode-se dizer que a expansão no mercado norteamericano foi a preocupação primordial do Grupo neste período (Tabela 2).

TABELA 2 - ANO DE AQUISIÇÃO E/OU JOINT-VENTURE E LOCALIZAÇÃO DAS EMPRESAS DO GRUPO GERDAU NO MERCADO INTERNACIONAL - 1980-2008

\begin{tabular}{|c|c|c|c|}
\hline Ano & Empresa & Localização & Processo \\
\hline 1980 & Siderurgica Laisa & Montevideo - Uruguai & Aquisição \\
\hline 1989 & Courtice Steel Incorporation & Cambridge, ON - Canadá & Aquisição \\
\hline 1992 & Siderúrgica AZA & Santiago - Chile & Aquisição \\
\hline 1992 & INDAQ & Santiago - Chile & Aquisição \\
\hline 1995 & Manitoba Rolling Mills (MRM) & Selkirk, MB - Canadá & Aquisição \\
\hline 1997 & Sociedad Puntana S.A. (SIPSA) & Villa Mercedes - Argentina & Aquisição \\
\hline 1997 & SIPAR & Pérez - Argentina & Aquisição \\
\hline 1999 & AmeriSteel & Estados Unidos & Aquisição \\
\hline 2001 & Georgia Steel Mill & Cartersville, GA - Estados Unidos & Aquisição \\
\hline 2002 & Co-Steel & Estados Unidos & Fusão \\
\hline 2004 & Potter Form \& Tie & Belvidere, IL - Estados Unidos & Aquisição \\
\hline 2004 & North Star Steel & Estados Unidos & Aquisição \\
\hline 2004 & Gate City Steel Inc./RJ Rebar Inc. & Indianápolis, IN - Estados Unidos & Aquisição \\
\hline 2004 & Cargill Inc. & Estados Unidos & Aquisição (Parcial) \\
\hline 2006 & Callaway Building Products & Knoxville, TN - Estados Unidos & Aquisição \\
\hline 2006 & Fargo Iron \& Metal Co. & Fargo, ND - Estados Unidos & Aquisição \\
\hline 2006 & Sheffield Steel Corporation & Estados Unidos & Aquisição \\
\hline 2006 & Empresa Siderurgica del Perú & Perú & Aquisição (Parcial) \\
\hline 2006 & Pacific Coast Steel & Estados Unidos & Joint-venture \\
\hline 2006 & GSB Acero & Guipúzcoa - Espanha & Aquisição \\
\hline 2007 & Siderúrgica Tultitlan & Cidade do México - México & Aquisição \\
\hline 2007 & Industrias Nacionales C.p.A. (INCA) & República Dominicana & Joint-venture \\
\hline 2007 & Valley Placers Inc. & Las Vegas, NV - Estados Unidos & Aquisição \\
\hline 2007 & Kaylani & Ásia & Joint-venture \\
\hline 2007 & Chaparral Steel* & Estados Unidos & Aquisição \\
\hline 2008 & Century Steel & Las Vegas, NV - Estados Unidos & Aquisição \\
\hline 2008 & Corporación Centroamericana del Acero & Guatemala e Honduras & Aquisição (Parcial) \\
\hline
\end{tabular}

FONTE: Elaboração dos autores a partir dos dados da GERDAU, 2009c.

Dentre as principais aquisições e parcerias realizadas após a fusão com a Co-Steel em 2002, cabe ressaltar: a aquisição da Potter Form \& Tie (2004), que possuía sete unidades nos Estados Unidos; a aquisição da North Star Steel (2004), que possuía quatro usinas produtoras de aços longos; a Cargill Inc. (2004); uma joint-venture com a Pacific Coast Steel e Bay Area Reinforcing, visando a compra da Pacific Coast Steel (2006); e, por fim, a aquisição da Chaparral Steel ${ }^{59}$ (2007), considerada a maior transação do Grupo Gerdau.

Os resultados destas aquisições e expansão no mercado internacional, aliadas às aquisições e construções internas no país de origem deram impulso significativo ao volume total de produção, como se pode observar pela Figura 2.

\footnotetext{
59 A aquisição da Chaparral Steel é considerada a maior transação do Grupo Gerdau. Os ativos da empresa foram avaliados em US $\$ 4,22$ bilhões. A siderúrgica é a segunda maior produtora de aço estrutural na América do Norte e também uma grande produtora de barras de aço e opera duas minimills localizadas em Midlothian (TX) e Dinwiddie County (VI).
} 


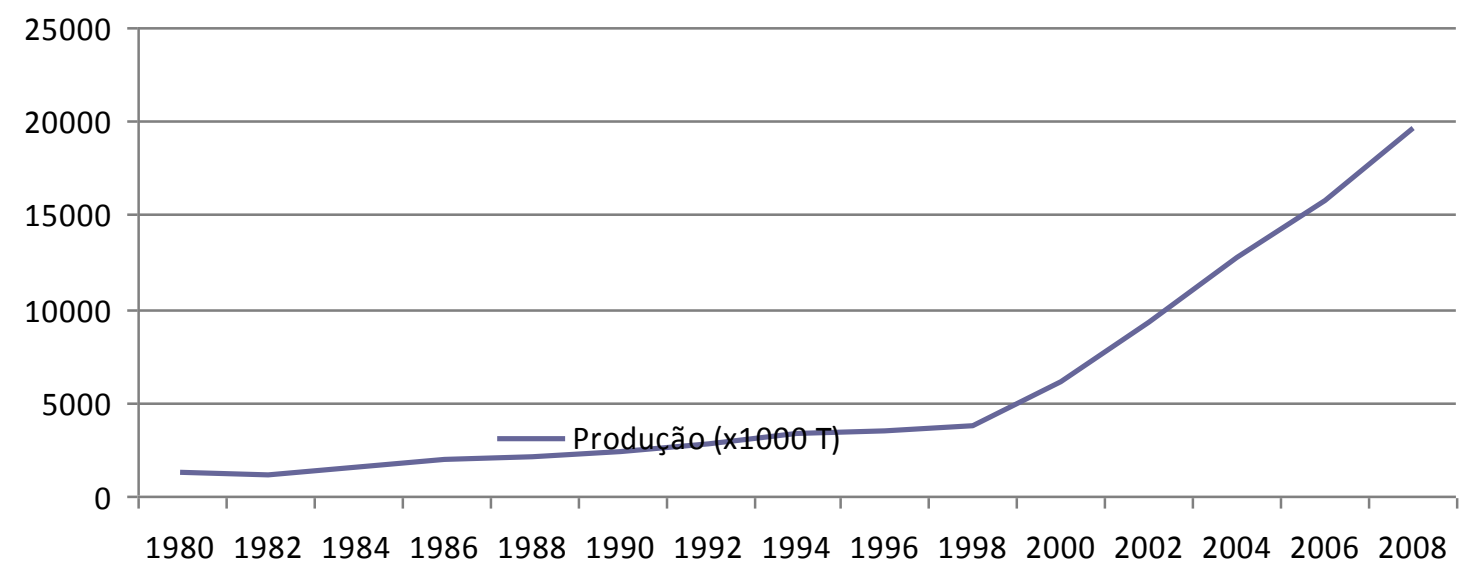

FONTE: Elaboração dos autores a partir dos dados da GERDAU, 2009a (não incluem joint-ventures).

\section{CONCLUSÃO}

O Grupo Gerdau iniciou suas atividades em 1901 através da aquisição da Fábrica de Pregos Pontas de Paris, em Porto Alegre, RS. Em 1948, em decorrência da Segunda Guerra Mundial, a oferta de matéria-prima ficou comprometida, levando à compra da então chamada Siderúrgica Riograndense, visando suprir a falta de matéria-prima para a produção dos pregos. Contudo, o que não se imaginava, era que a siderurgia viraria o "carro-chefe" da empresa. A partir da entrada no ramo siderúrgico per se, a expansão do Grupo é rápida, utilizando, principalmente, as aquisições como forma de entrada nos mercados.

A partir de 1980, o Grupo entrou no processo de expansão internacional, realizando aquisições de diversas siderúrgicas, iniciando com a Laisa (Uruguai, 1980), Courtice Steel Inc. e MRM (Canadá, 1989 e 1995, respectivamente), Sipsa e Sipar (Argentina, 1997 e 1998, respectivamente) e AmeriSteel (Estados Unidos, 1999). Após a entrada no mercado estadunidense em 1999, embora a estratégia adotada pela empresa tenha visado a expansão nos âmbitos interno e externo, fica evidente que houve um enfoque nos Estados Unidos como principal destino dos investimentos. Dentre os principais negócios realizados no exterior na década de 2000, o mais importante foi a aquisição da Chaparral Steel, nos Estados Unidos, no valor de US\$4,22 bilhões. Como ficou demonstrado na Figura 2, o crescimento da produção da empresa cresceu de forma exponencial a partir de 1999, ficando evidente que a 
entrada no mercado norte-americano foi o principal passo em termos de expansão comercial e produtiva do Grupo.

Dessa forma, fica evidente que a diversificação dos produtos, as aquisições e a internacionalização da empresa, podem ser consideradas as principais estratégias adotadas pelo Grupo e, também, responsáveis pelo expressivo crescimento apresentado ao longo dos anos, em especial após a década de 1980, quando o processo de expansão internacional teve início.

\section{REFERÊNCIAS}

BARBOSA, F. A Internacionalização do Grupo Gerdau: um estudo de caso. Dissertação de Mestrado - Departamento de Administração, PUC-RJ. Rio de Janeiro, 2004.

BRESSER-PEREIRA, L.C. Desenvolvimento e Crise no Brasil. São Paulo: Editora 34, 2003.

CORREIA, D.; LIMA, G.T. A internacionalização produtiva das empresas brasileiras: breve descrição e análise geral. Anais Eletrônicos em CD-Rom do Workshop sobre internacionalização das empresas: desafios e oportunidades para países emergentes, FEAUSP, 2006.

DALLA COSTA, A.J.; PESSALI, H.F. A experiência de internacionalização da Petrobras. VII Congresso Brasileiro de História Econômica e VIII Conferência Internacional de História de Empresas. Aracaju-SE, 2 a 7 de setembro de 2007 (versão eletrônica).

GERDAU Chama Empreendora: A história e a cultura do Grupo Gerdau - 1901-2001. Disponível em http://www.gerdau.com/grupo-gerdau/memoria-gerdau-centrodocumentacao.aspx, 2001.

GERDAU (2009a) Memória Gerdau/Desempenho Histórico. Disponível em http://www.gerdau.com/grupo-gerdau/memoria-gerdau-desempenho-historico.aspx, acesso em 19/03/2009.

GERDAU (2009b) Memória Gerdau/Nossa História. Disponível em http://www.gerdau.com.br/port/agerdau/download/cronologia_outubro2008.pdf, acesso em 28/03/2009.

GERDAU (2009c) Notícias Gerdau: Menor demanda de aço reduz vendas da Gerdau no quarto trimestre de 2008. Disponível em http://www.gerdau.com.br/port/noticia/noticias_geral_pop.asp?cd_noticias=2294\&categori $\mathrm{a}=8 \&$ site $=$ SI, acesso em 29/03/2009.

IGLESIAS, R.M.; VEIGA, P.M. Promoção de Exportações via Internacionalização das Firmas de Capital Brasileiro. Fundação Centro de Estudos no Comércio Exterior, Rio de Janeiro, 2002.

PENROSE, E. A Teoria do Crescimento da Firma. Campinas: UNICAMP, 2006.

WORLD STEEL (ASSOCIATION) Steel in Figures: Top Steel Producers 2007. Disponível em http://www.worldsteel.org/, acesso em: 16/03/2009. 
